\title{
EL TEATRO-FORO COMO HERRAMIENTA DIDÁCTICA PARA EL CAMBIO EDUCATIVO
}

\section{(THE FORUM-THEATRE AS A DIDACTIC TOOL FOR THE EDUCATIONAL} CHANGE)

Teresa García Gómez

Universidad de Almería

César de Vicente Hernando

Universidad Autónoma de Madrid

DOI: $10.5944 / e d u c X X 1.23347$

Cómo referenciar este artículo/How to reference this article:

García Gómez, T., y de Vicente Hernando, C. (2020). El Teatro-Foro como herramienta didáctica para el cambio educativo. Educación XX1, 23(1), 437-458, doi: 10.5944/educXX1.23347

García Gómez, T., \& de Vicente Hernando, C. (2020). The Forum-Theatre as a didactic tool for the educational change. Educación XX1, 23(1), 437-458, doi: 10.5944/educXX1.23347

\section{RESUMEN}

Este trabajo presenta una experiencia de innovación docente en el marco de la formación inicial de maestros y maestras. Dicha innovación consiste en la incorporación de una técnica del Teatro del Oprimido, concretamente el Teatro-Foro, como estrategia didáctica en la enseñanza universitaria con el objetivo de que el alumnado conozca desde una perspectiva crítica la realidad educativa, analice las relaciones de poder y estructuras de dominación en los centros de enseñanza y actúe para su transformación con el fin de construir y desarrollar una educación justa y democrática. Dicha experiencia se viene realizando durante cuatro cursos académicos con alumnado de primero del Grado en Educación Primaria en la Universidad de Almería. Para dar cuenta de esta experiencia, en primer lugar, abordamos los orígenes, el desarrollo y la metodología del Teatro- 
Foro. Posteriormente, situamos dicha experiencia de formación inicial en el marco de la pedagogía crítica, acorde con las finalidades de esta, y más específicamente en el marco de la educación problematizadora de Paulo Freire, abordando qué posibilidades nos ofrece el Teatro-Foro para el desarrollo de esta educación. A continuación, contextualizamos esta experiencia de innovación, especificando los objetivos de la misma, su desarrollo y los temas y conflictos abordados. Por último, en el apartado de conclusiones, señalamos que las dualidades (teoría-práctica, investigacióndocencia, enseñanza-aprendizaje, aprendizaje individual-aprendizaje colectivo, etc.) deben integrarse en un nuevo modelo para la formación inicial docente que el Teatro-Foro, como herramienta metodológica, facilita.

\section{PALABRAS CLAVE}

Innovación pedagógica; formación inicial docente; pedagogía crítica; Teatro del Oprimido, Teatro-Foro.

\section{ABSTRACT}

This article presents an experience of educational innovation in the framework of the initial training of teachers. This innovation consists of the incorporation of techniques from the Theatre of the Oppressed, specifically the Forum-Theatre, as a didactic strategy of university education. The objective is for students to know, from a critical perspective, the educational reality, to analyze the relations of power and structures of domination in the education centers and to act for transformation in order to construct and to develop a just and democratic education. This experience was carried out during four academic courses with first year students the Degree in Primary Education at the University of Almeria.

To undertake this experience, first we approached the origin, the development and the methodology of the Forum-Theatre. Later, we placed this experience of initial training in the framework of critical pedagogy, according to the purposes of the same, and more specifically in the Problemposing of Paulo Freire, approaching the possibilities offered to us by the Forum-Theatre for development. Next, it contextualizes this experience of innovation, specifying the aims of the same, the development and the topics and approached conflicts. Finally, in the paragraph of conclusions, we indicate that the dualities (theory-practice, research-teaching, educationlearning, individual learning-collective learning, etc.) must join a new model for the initial educational training that the Forum-Theatre, as methodological tool, facilitates. 


\section{KEYWORDS}

Educational innovation; initial teacher training; critical pedagogy, Theatre of the Oppressed; Forum-Theatre.

\section{ORÍGENES, DESARROLLO Y METODOLOGÍA DEL TEATRO-FORO}

El Teatro-Foro es un modo del Teatro del Oprimido ${ }^{1}$, es decir, un trabajo escénico destinado al análisis, denuncia y crítica de las relaciones de poder, que conformó el director de escena brasileño Augusto Boal durante los años setenta, que se distingue de los otros modos de discurso teatral político, en primer lugar, por la conversión del espectador tradicional, que asiste a una representación teatral sin posibilidad de intervenir en ella, en participante; y, en segundo lugar, por el control absoluto, por parte de la comunidad que realiza la sesión de teatro-foro, de la dramaturgia, la puesta en escena y el desarrollo escénico de la pieza representada. Esta disolución de las fronteras del teatro convencional, tanto la que divide a los actores de los espectadores como la que separa las autorías escénicas de las prácticas sociales e ideas de los asistentes, abre la posibilidad de transformar la realidad a través de una escena interpuesta, como si la representación fuera un ensayo previo antes de actuar en la realidad misma.

\section{Orígenes}

Boal llega al Teatro-Foro después de desarrollar una amplia labor educativa por numerosos países latinoamericanos, en alguno de los cuales participa en programas gubernamentales de alfabetización integral, como el que dirige Alfonso Lizarzaburu en Perú, denominados ALFIN, que sigue el método planteado por Paulo Freire. Boal unifica bajo el nombre de "Oprimido" las diversas formas que adoptará sus técnicas a partir, claro está, del libro fundamental de Freire: Pedagogía del oprimido, aparecido en 1968 pero que llevaba funcionando a lo largo de los años sesenta en diversos países de América y África².

En una entrevista que le hace Emil Copfermann en 1977, Boal destaca el hecho de que el teatro, en los países dominados por el colonialismo y el imperialismo, se ha utilizado y se sigue utilizando como forma de liberación: "la gente lo utiliza para tratar de cumplir un acto liberador" (Boal, 1982, p. 227). El teatro se convierte en una herramienta con la que pueden romperse las formas de dominación bajo las que se vive, distinguiéndose así del uso del teatro como mero modo de divertimento espectacular o de consumo 
reproductivo de las ideologías dominantes. Igualmente del teatro como disposición reflexiva sobre el mundo pero que está limitada a la visión unilateral de la autoría dramatúrgica y de puesta en escena extendida en el mundo occidental y en tanto que piensa, y no actúa, sobre la acción representada, y lo hace, además, con posterioridad al acto teatral.

El Teatro-Foro, por tanto, se funda en dos ideas matrices: la primera, la liberación al espectador de su condición de espectador ${ }^{3}$, como se trata, en la pedagogía crítica, de liberar al alumnado de su condición de alumnado la segunda, la devolución al pueblo de los medios de producción, como se trata, en la pedagogía crítica, de devolver al alumnado los medios de producción educativa (conocimientos y técnicas). Es significativo el hecho de que es en el acto mismo de la realización escénica del Teatro-Foro donde el conflicto presentado puede transformarse, lo que desborda propiamente lo teatral para configurarse como un espacio de lo social.

\section{Desarrollo}

El Teatro-Foro, que nació a mediados de los años setenta como respuesta "a estímulos y necesidades estéticas y sociales" (Boal, 1982, p. 77), se describe ampliamente por primera vez en el tomo segundo de Teatro del oprimido, sin embargo, se ha convertido en un medio técnico integrado en otras técnicas que desarrolló posteriormente.

Es un dispositivo escénico en las técnicas del Arco Iris del Deseo, elaboradas durante los años ochenta en Europa, en el que se pretende descubrir y analizar las formas de dominación que han sido incorporadas en los individuos y de la que no hay consciencia. En este complejo dispositivo de trabajo teatral, el Teatro-Foro aparece como un elemento más dentro de las diferentes configuraciones de diversas técnicas prospectivas, introspectivas y de extraversión. De la misma manera, aparece como eje central entre las técnicas del Teatro Legislativo, elaboradas a finales de los ochenta y comienzos de los noventa, que sirven para proponer leyes y normas que puedan ser elevadas a parlamentos y consejos municipales.

Aunque siempre estuvo vinculado con prácticas educativas y de trabajo social, en 1986 y 1987 Boal estuvo vinculado con un equipo de pedagogos y animadores socioculturales para la realización de talleres de Teatro del Oprimido en la CIEP (Centro Integrado de Educación Popular), en la Universidad de San Juan de Puerto Rico y en Sydney (Nueva Escocia) en Canadá. Los Centros de Teatro del Oprimido (CTO) que existen en todo el mundo funcionan, por una parte, como producción de conocimientos humanísticos y, por otra, de modelos de trabajo social colectivo. 


\section{Metodología}

En primer lugar, se conforma una dramaturgia, es decir, se define un conflicto, un lugar y un espacio en los que se da el mismo, los personajes que forman parte de él -bien caracterizados social e ideológicamente-, las acciones que se desarrollan, los diálogos o monólogos que articulan el conflicto, y un cierre en falso. Boal señala que "las soluciones propuestas por el protagonista deben contener por los menos un error político o social que será analizado en el <foro>" (Boal, 1982, p. 38). Se produce así un "texto" teatral, lo que se llamará en adelante, una "pieza anti-modelo" en tanto que lo que se desarrolla y concluye en ella debe ser radicalmente transformado, solucionado.

En segundo lugar, se propone una puesta en escena del "texto" teatral que sea representativa, no decorativa; significativa del conflicto, no ilustrativa; y expresiva, no ornamental. Y sobre todo clara. A diferencia de lo que pasa en otros sistemas de interpretación actoral, el trabajo de los actores en el Teatro-Foro requiere que los personajes sean reconocidos visualmente, que los actores realicen movimientos que expresen bien su ideología, su trabajo, su función social, su profesión, etc., y, más importante aún, "que el personaje evolucione según leyes, que efectúe actos" (Boal, 1982, p. 38), es decir, encuentre una lógica vital que justifique lo que puede y lo que no puede hacerse con él.

En tercer lugar, se realiza la sesión de teatro-foro dividida en dos partes: una, la representación de la pieza según el modelo tradicional. A continuación se pregunta a los espectadores, mediante un mediador (el comodín $)^{5}$, si están de acuerdo con la solución propuesta. A partir de este momento se desarrolla una dinámica de intervención sobre la escena en la que la participación física de los asistentes es fundamental: se trata de sustituir al protagonista de la pieza, o a alguno de los personajes fundamentales en el desarrollo del conflicto, en el momento de la obra en la que lo crea oportuno. La obra se repite desde el comienzo y cuando el espect-actor que ha salido quiere intervenir, para la escena y se intercambia por el que ha representado hasta ese momento el papel, que -sin embargono se retira, sino que permanece junto al nuevo actor, para corregirle en el caso de que altere alguna de los rasgos que lo definen, evitando -de este modo- las "soluciones mágicas" que supondría, por ejemplo, establecer una salida del conflicto que no tuviera en cuenta las condiciones específicas que ha definido la pieza (magia, lógicas idealistas, etc.). En esta versión primera del Teatro-Foro, el resto de personajes cambian su posición y, ante la intervención del espect-actor, se convierten en agentes represores que obligan a su vez a la persona que interviene a afrontar este bloqueo en la solución que estaba proponiendo. El juego escénico del "foro" termina para 
el espect-actor cuando renuncia, entonces el actor retoma su papel y la pieza vuelve a desarrollarse hasta el final ya conocido hasta que otro espect-actor trata de intervenir en la escena intercambiándose por el protagonista u otros personajes, y repitiéndose la dinámica hasta que la opresión se resuelve. En este momento, dice Boal, los participantes han modificado el mundo inicial de la pieza y el conocimiento que resultará de esta indagación será necesariamente el $<$ mejor conocimiento $>$ que este grupo social y humano podrá alcanzar.

Finalmente, la comunidad formada en esta sesión de teatro-foro es invitada a construir un "modelo de acción futura" que será interpretado solamente por los espect-actores y que les debe llevar a configurar un mundo posible distinto, liberado de la opresión sobre la que se ha trabajado.

Pasar del teatro para el pueblo al teatro del pueblo, como pedía el director de escena (Boal, 1982a, p. 225), significa que en esta dinámica de Teatro-Foro el espect-actor no solamente debe trabajar los gestos sociales sino la improvisación, lo que le permite establecer un nuevo horizonte social donde las relaciones de dominación hayan sido desarticuladas.

Gran parte del Teatro-Foro se sustenta en la Pedagogía del oprimido de Paulo Freire por lo que se hace necesario señalar la dimensión de la misma en relación, a su vez, con la formación inicial del profesorado para el cambio educativo.

\section{LA FORMACIÓN INICIAL EN EL MARCO DE LA PEDAGOGÍA CRÍTICA Y EL TEATRO-FORO}

Freire (2005, p. 33) señalaba la politicidad de la educación para referirse a la cualidad que tiene la educación de ser política, indicando que la discusión y el análisis está en saber de qué política se trata, es decir, la educación a favor de qué y quién o quiénes actúan, o lo que es lo mismo en contra de qué y de quién o quiénes actúan. Esta politicidad es la direccionalidad de la educación, que puede tomar dos caminos posibles: la educación como instrumento de dominación o la educación como instrumento para la emancipación ${ }^{6}$. En esta línea todo programa de formación inicial del profesorado estará enmarcado para potenciar un modelo u otro de escuela. Es decir, formaremos a futuros maestros y maestras para integrarse en el orden escolar y social actual o los formaremos para enfrentarse de forma crítica a la realidad con el objetivo de transformarla (Beyer y Zeichner citado por Popkewittz, 1990; Liston y Zeichner, 1997). En definitiva, un programa de formación comprometido con el mantenimiento o bien con el cambio de los modelos cultural, social, político, económico y escolar. En 
esta segunda opción se sitúa la pedagogía crítica, que coloca al ser humano en el centro del pensamiento y de las acciones para formar al profesorado como agente activo y comprometido éticamente en la construcción de una sociedad justa, una sociedad basada en una ética de la humanización y solidaridad y no en una ética del mercado (Freire, 2001; Huerta-Charles, 2008). De ahí su preocupación por los colectivos oprimidos, dominados, excluidos e invisibilizados, de ahí su denuncia de aquellas experiencias educativas que perpetúan y legitiman estos estados de dominación, de ahí su compromiso por transformar la educación, que no puede estar al margen de las estructuras económicas, políticas y sociales que envuelven a la escuela y que generan dicha dominación.

Por tanto, la pedagogía crítica es defensora explícita de la naturaleza política de la educación y tiene como objetivo la emancipación de los sujetos. Para ello se centra en la compresión de los mecanismos de opresión y dominación para su posterior transformación. En este sentido debe entenderse la pedagogía crítica como parte de un proyecto ético y político más amplio vinculado al desarrollo de la justicia social y económica y con la construcción de la democracia. De ahí que uno de los primeros y grandes objetivos de la pedagogía crítica sea concientizar a los individuos, pensar el mundo en el que vivimos, pensarlo críticamente, cuestionando concepciones, asunciones y prácticas, así como las consecuencias de ellas.

Para ello el currículum de formación del profesorado debe diseñarse y desarrollarse como una forma de política cultural, es decir, un currículum que hace de lo social, lo cultural, lo político y lo económico categorías esenciales para la comprensión de la escuela actual (Giroux y McLaren, 1990, p. 256), que posibilita al profesorado el cuestionamiento de los discursos educativos oficiales y las prácticas de dominación tradicionales dentro y fuera de la escuela, yendo más allá del lenguaje de la crítica, construyendo un lenguaje de la posibilidad (Freire, 1997; Giroux y McLaren, 1990, p. 256). Este lenguaje es el de evidenciar la existencia o crear otras prácticas docentes alternativas exentas de dominación dentro y fuera de la escuela. Estos lenguajes -el de la crítica y el de la transformación- según Giroux y McLaren (1990, pp. 256-257), implican la creación en los programas de formación del profesorado de un nuevo espacio público sustentado en la práctica democrática, en la libertad y la justicia social. Esto requiere formar a las futuras y los futuros profesionales de la educación como intelectuales críticos capaces de afirmar y de practicar el discurso de la libertad y de la democracia (Giroux y McLaren, 1990, p. 245) en el proceso de adquirir una conciencia individual y colectiva para la creación de un espacio contrapúblico democrático (Giroux y McLaren, 1990), en el que estén presentes las voces del estudiantado y de la comunidad, en el que se pueda discutir críticamente el conocimiento, generarlo, aprehenderlo y adquirir las habilidades necesarias 
para vivir una verdadera democracia en interés de una comunidad justa y con el objetivo de desarrollar una pedagogía liberadora. Freire (1992) confronta la educación bancaria a la educación problematizadora, en la que profesorado y alumnado son sujetos activos en el proceso de conocimiento, produciéndose este en la confrontación realidad-mundo. Es una educación crítica, que problematiza el conocimiento y al propio docente, ya que como afirma Freire (1975a, p. 94):

la problematización es dialéctica, que sería imposible que alguien la estableciera, sin comprometerse con el proceso. Nadie problematiza algo a alguien y permanece, al mismo tiempo, como mero espectador. Aun cuando, metodológicamente, prefiera mantenerse en silencio al presentar el hecho-problema, en cuanto los educandos lo captan, lo analizan, lo comprenden, estará siendo también problematizado.

La educación problematizadora, sustentada en el diálogo, busca la trasformación de las estructuras opresoras que permita la liberación de los seres humanos. A través de esta educación problematizadora se liberan tanto profesorado como alumnado, ya que en su proceso se concientizan ambos a través de la praxis, que es la unión indisociable de teoríapráctica, de reflexión y acción sobre la realidad para transformarla. Una educación problematizadora en la formación inicial de futuros maestros y maestras implicaría la transformación de los procesos educativos tanto en las escuelas como en la universidad, sería la formación del ser para la transformación de este y de su realidad-mundo, al estar contextualizada y partir de problemáticas reales y concretas y potenciar el pensamiento crítico y creativo.

Para este objetivo, desarrollar una pedagogía liberadora, es necesario atender a los problemas y experiencias concretas de la vida diaria. Problemas en conexión con lo social, lo económico y lo político y que el profesorado debe comprenderlos con el objeto de desarrollar la conciencia social. Por tanto, es un currículum basado en problemas y en conexión con el ámbito comunitario.

La pedagogía crítica entiende la enseñanza como una actividad problematizadora para la emancipación individual y colectiva, inserta en un campo de luchas por la justicia y la igualdad a través de procedimientos educativos democráticos en conexión con otros ámbitos y movimientos sociales. Desde el marco de esta pedagogía

la escuela y la educación del profesor son elementos cruciales en el proceso de consecución de una sociedad más justa. Para ello, la escuela debe proponerse como objetivo prioritario cultivar la capacidad 
de pensar críticamente sobre el orden social. El profesor es considerado como un intelectual transformador, con un claro compromiso político de provocar la formación de la conciencia de los ciudadanos en el análisis crítico del orden social de la comunidad en que viven. El profesor es a la vez un educador y un activista político, en el sentido de intervenir abiertamente en el análisis y debate de los asuntos públicos, así como por su pretensión de provocar en los alumnos el interés y compromiso crítico con los problemas colectivos (Pérez Gómez, 1992, p. 423).

La pedagogía crítica entiende la formación del profesorado como praxis, sustentada en los principios de democracia, justicia, igualdad y autonomía, de orientación crítica reflexiva y comprometida desde un punto de vista sociopolítico para que pueda contribuir al proceso de mejora de la enseñanza y al cambio social (Beyer, 1988 citado por Liston y Zeichner, 1997, p. 57). Una formación en el marco de la reflexión crítica para que las futuras maestras y maestros pueden empezar a identificar las relaciones que existen entre el aula y las condiciones educativas, sociales, económicas y políticas más amplias que influyen en la práctica del aula y la determinan. Esto hace necesario un enfoque de formación inicial sustentado en la dialéctica teoría-práctica, pensamiento-acción, prácticas y currículum de formación, que supere la separación y disociación entre escuela y universidad, entre escuela-comunidad-universidad.

Un programa de formación inicial en el marco de la pedagogía crítica, utilizando como herramienta metodológica el Teatro-Foro, nos va a posibilitar los siguientes objetivos:

a) Abrir un espacio de discusión en torno a la función de la escuela en el orden social imperante en tanto que trasmisora de ideas, imágenes y representaciones sociales que el alumnado puede experimentar no solo intelectualmente sino también físicamente puesto que en su calidad de espec-actor debe sumergirse en las condiciones especificadas en la anti-pieza y, desde ahí, tratar de modificar ese conjunto ideológico. Se ponen así en discusión las múltiples formas de dominación -género, clase social, orientación sexual...-, que permiten que el alumnado desarrolle una perspectiva crítica, generando a su vez discursos y prácticas contrahegemónicas capaces de transformar las relaciones de dominación y opresión. Explicitar y analizar las relaciones entre la ideología y el poder dominantes y la cultura escolar.

b) Reflexionar sobre la relación teoría-práctica, deshaciendo el equívoco habitual que les confiere dimensiones radicalmente diferentes y no relaciones de convergencia y consecutividad. El 
proceso dialéctico que se da en el proceso de desarrollo del TeatroForo requiere tanto el diseño teórico de la problemática como la realización práctica de la representación escénica.

c) Desarrollar un imaginario crítico y creativo en los que proyectar nuevas ideas y acciones, entendiendo la imaginación como "el acto de ver lo que todavía no está ahí, especulando sobre cómo podría ocurrir, rescribiendo lo que ha venido antes y abriéndose paso a través de "lo real"; es pensar lo improbable como posible" (Aronowitz y Bratsis, 2006 citados por Weiner, 2008, pp. 90-91). Este imaginario crítico permitirá pensar y ensayar acciones que se dirijan de forma efectiva y colectiva a la conquista de espacios de libertad, explorando nuestro estar en el mundo. Así, "nos unimos a la búsqueda de nuevos modos de ser humanos, expandidos, más justos e interconectados" (Kincheloe, 2008, p. 58).

d) Procesos participativos colectivos, que en los términos de Freire sería un aprendizaje dialógico, para indagar en las causas de la opresión y dominación, y actuar en las relaciones de poder y estructuras que las provocan desde las comunidades de base (centros educativos, asociaciones, etc.), experimentando ideas, hipótesis y teorías.

e) Experimentar la enseñanza como una práctica reflexiva crítica (Zeichner, 1995; Stenhouse, 1996; Grundy, 1998; etc.), en la medida en que los futuros maestros y maestras serán sujetos de su formación y no objetos, buscando y comprobando en la acción las prácticas que favorecen la justicia social y la democracia en la enseñanza, de la misma manera que las personas que participan en el Teatro-Foro serán sujetos en la escena y no objetos, y buscarán en la acción escénica modos de ruptura de las relaciones de poder.

f) Analizar y cuestionar las estructuras institucionales de las escuelas, desentrañar el sentido social y político al que responden, los límites que estas imponen a la práctica y pensamiento docente (Contreras, 1997), al igual que el Teatro-Foro hizo lo mismo con la institución del teatro y el dispositivo hegemónico de la representación teatral dividida.

g) Posicionarse ante los problemas escolares y sociales en sus contextos socio-históricos, intervenir críticamente y asumir las consecuencias de las acciones, dado que el Teatro-Foro se constituye como laboratorio de la imaginación social donde se ensayan respuestas que, luego, pueden llevarse a la realidad. Como señala Freire (1975a) 
la reflexión crítica va dirigida a la acción, es praxis. Es una reflexión procesual, una reflexión en, sobre y para la acción.

h) Conseguir un conocimiento contextualizado, una interpretación y compresión situacional, en términos de Elliott (1993 citado por Pérez Gómez, 1995), puesto que el Teatro-Foro no impone ninguna precondición ideológica.

\section{CONTEXTUALIZANDO UNA EXPERIENCIA INNOVADORA}

El Teatro-Foro es un sistema de trabajo teatral muy extendido en la actualidad. En centros sociales, ayuntamientos, asociaciones vecinales, etc. su uso responde a necesidades políticas de la ciudadanía que, indefectiblemente, se ha trasladado a la universidad. Sin embargo, no conocemos que esta forma de Teatro Político se esté utilizando en los planes de estudio universitarios al margen de lo que se expone respecto a la Universidad de Almería. Existen, sin embargo, otras experiencias educativas contempladas en las enseñanzas no oficiales. En el año académico 20092010 se inició "El teatro político: teoría y práctica" en la Facultad de Ciencias Políticas y Sociología de la Universidad Complutense de Madrid que presentaba el Teatro-Foro como herramienta de análisis de la realidad social a través del arte. Este curso sigue funcionando en la actualidad. En el año académico 2013-2014 se desarrolló un proceso de documentación seguido en un taller de Teatro Foro desarrollado con estudiantes y profesorado de la Facultad de Educación de la Universidad de Cantabria (España), una experiencia de formación que emerge del interés por enriquecer la formación inicial del profesorado a partir de herramientas y contenidos que sitúan al frente la intervención o agencia de los futuros maestros y maestras para transformar las escuelas (Calvo, Haya y Ceballos, 2015). En el curso 20162017, organizado por el Aula laboratorio de Teatro Social, en la Facultad de Ciencias Políticas y Sociología de la Universidad Complutense de Madrid, se presentó el seminario "El Teatro Foro como herramienta de intervención e investigación social”. En la Universidad Nacional de Costa Rica la técnica se utiliza como una herramienta colectiva de debate y reflexión grupal en torno a determinadas problemáticas sociales. La técnica se aplica con estudiantes de la universidad como continuación de dos cursos pasados cuyo nombre era Teatro del Oprimido: una perspectiva práctica del humanismo (20162018) y en el marco del proyecto Una ventana al teatro: aportes artísticos en la mediación pedagógica (2015-2017).

El Teatro-Foro es una estrategia metodológica que se emplea para trabajar la asignatura "Didáctica y Organización de la Educación Primaria I" en el Grado en Educación Primaria. Es una asignatura básica 
cuatrimestral de primer curso de 6 créditos ECTS, que se imparte durante el primer cuatrimestre. El empleo del Teatro-Foro como recurso metodológico pretende lograr distintos objetivos propuestos en la asignatura de Didáctica y Organización de la Educación Primaria I, entre ellos:

1. Conocer la realidad educativa desde una perspectiva crítica y elaborar herramientas para la construcción y desarrollo de escuelas democráticas participativas y justas.

2. Comprender, analizar y valorar las dimensiones éticas y políticas implícitas en los procesos educativos y en la organización y gestión de los centros educativos.

3. Crear respuestas alternativas ante distintas prácticas educativas injustas y antidemocráticas.

Asimismo, no podemos desligar el uso del Teatro-Foro como estrategia didáctica de los contenidos que se trabajan en el marco de la asignatura y del conjunto de recursos metodológicos que se utilizan, así como de las formas de evaluación.

Por una parte, los contenidos se seleccionan atendiendo a otras características, coincidentes algunas de ellas con los componentes que Carbonell (2001) denomina conocimiento innovador, tales como contenidos que permitan una formación más integral, por lo que atienden a aspectos éticos, creativos, sociales, emocionales, etc.; contenidos relevantes al considerar un capital cultural necesario para entender y transformar el orden escolar; contenidos interculturales e inclusivos -género, clase social, etnia, etc.-, incorporando una perspectiva contrahegemónica; contenidos cuestionadores, que problematizan la realidad (Freire, 1992) para potenciar el pensamiento reflexivo, la comprensión y la perspectiva crítica, así como la emancipación de los sujetos y su independencia intelectual; y contenidos que interpelan a la realidad educativa y a través de los cuales se buscan fórmulas para la transformación.

Los contenidos que se proponen para enseñar pretenden provocar la concientización del alumnado como futuros maestros y maestras como agentes de cambio en un proyecto de escuela democrático y favorecedor de la justicia social, para ello los contenidos nos sirven para conocer críticamente la realidad escolar como construcción socio-histórica, política y económica, reflejo de la estructura social, y proyectar otra realidad escolar y social, de ahí que se trabaje simultáneamente lo que es y lo que puede ser, avalándonos con prácticas educativas concretas. 
Los contenidos se desarrollarán, atendiendo a que trabajamos con alumnado recién ingresado en la universidad, realizando un análisis paralelo que facilite el conocimiento de la realidad educativa y a partir de esta construir otra desde la democracia y la justicia, ya que solo se pueden promover cambios con sentido y efectivos en el orden escolar si se conoce este en profundidad. Por esta razón nos vamos moviendo entre la realidad existente y otra realidad. Grosso modo, situamos el inicio en el derecho a la educación, que nos permitirá comprender la necesidad de un urgente cambio que elimine las desigualdades educativas y sociales, haciendo real la justicia educativa y social desde procesos democráticos participativos. La justicia y la democracia son los principios sobre los que giran el resto de temas que integran el programa, por ello trabajaremos estos conceptos para partir de un lenguaje común y de significados compartidos. Este primer tema constituye el pilar sobre el que se sustentan los otros (funciones de la escuela, currículum, recursos organizativos, participación y autonomía de la escuela).

Por otra parte, las estrategias metodológicas se enmarcan dentro de los llamados métodos participativos, que requieren la implicación, el compromiso y la responsabilidad ante el aprendizaje, que nos permitirán provocar aprendizajes más significativos y relevantes, con oportunidad de transferirlos a contextos diversos y heterogéneos. Partimos de que la participación es un derecho, y en su ejercicio está la posibilidad de desarrollar la conciencia crítica y la transformación individual, colectiva y social. La participación posibilita pasar de relaciones de dependencia, paternalistas y verticales a una cultura democrática con protagonismo real de las personas (Gutiérrez y Prieto, 2002, p. 46). Asimismo, posibilita la comunicación, el diálogo, la discusión y reflexión colectiva para transformar las prácticas hegemónicas; favorece una evaluación formativa y permanente (autoevaluación y coevaluación); así como la creatividad expresiva (Gutiérrez y Prieto, 2002, p. 47). Para ello hay que partir de la realidad, promover actitudes críticas y creativas, generar espacios de expresión y de comunicación, desarrollar la investigación como parte de la enseñanza, buscar la producción de conocimientos y atender a los procesos buscando resultados. Todo ello utilizando distintos recursos didácticos de diferentes soportes (textos, música, vídeos, poesía, cómic, etc.).

\section{Cronología de la experiencia: incorporación del Teatro-Foro como estrategia metodológica}

El Teatro-Foro, como hemos apuntado, es una de las técnicas del Teatro del Oprimido de Augusto Boal, que comenzamos a utilizarlo como estrategia didáctica en la enseñanza universitaria en el curso académico 
2013-2014, con el objetivo de buscar soluciones a algunos problemas que veníamos detectando años anteriores en el desarrollo de las clases. Por ello buscábamos otros mecanismos de participación en el aula, ya que esta se venía reduciendo a un grupo de alumnos y alumnas, de manera que se rompieran silencios y se desactivaran ausencias, que nos permitiera conocer las ideas, creencias, problemáticas y posicionamientos del alumnado que no intervenía; posibilitar otra relación con la asignatura, pasando de lo abstracto para los estudiantes a lo concreto, de manera que encontraran un sentido y utilidad a las teorías y conceptos trabajados en clase; y posibilitar otras experiencias de aprendizaje, que no estuvieran inicial y fundamentalmente mediadas por la palabra.

El Teatro-Foro como estrategia didáctica la realizamos una vez trabajado el primer tema del programa, La educación como construcción de la democracia y la justicia social, para que la teoría pase a la acción, en una sesión que tiene una duración de tres a cuatro horas. El conflicto ${ }^{8}$ que se trata en el Teatro-Foro se da en el ámbito educativo, definido de forma clara y realista, para trabajar los contenidos de educación democrática y justicia social, que forman parte de dicho tema, en tanto que el TeatroForo propicia la participación de todas las personas asistentes en la resolución del conflicto desde una interacción horizontal y sin jerarquías. Así por ejemplo los temas planteados en relación a la evaluación final, centrada en el resultado sin posibilidad de utilizarla como orientadora del aprendizaje; al tratamiento de contenidos solo de la cultura dominante excluyentes de otras culturas presentes en el aula; a la toma de decisiones jerárquicas que elimina la posibilidad de participación del alumnado y de la comunidad educativa, a la discriminación y exclusión de una alumna trans y a los procesos de enseñanza centrados en la transmisión de los contenidos recogidos en los libros de texto, etc., son tratados mediante el mecanismo del Teatro-Foro como procesos de constitución democrática y de transformación de las relaciones de poder que se dan en el ámbito educativo. El planteamiento de dichos conflictos visibiliza las estructuras y procedimientos propios de escuelas no democráticas, permite debatir sobre ellos y actuar para la erradicación de los mismos desde los planteamientos de escuelas democráticas (García Gómez, 2018) y justicia social en educación, concretamente justicia curricular (Connell, 1997).

Asimismo, el trabajo de los contenidos de escuelas democráticas y justicia social en educación va ligado a potenciar el desarrollo tanto de competencias generales, tales como: capacidad para resolver conflictos, comunicación oral, capacidad de crítica y autocrítica, trabajo en equipo, compromiso ético, competencia social y ciudadanía global; y aplicación de conocimientos, como de competencias específicas: analizar la práctica docente y las condiciones institucionales que la enmarcan; 
promover acciones de educación en valores orientadas a la preparación de una ciudadanía activa y democrática; analizar la práctica docente y las condiciones institucionales que la enmarcan, así como las consecuencias de dicha práctica; conocer críticamente la realidad educativa para potenciar la democracia y la justicia en el ámbito educativo; promover acciones de educación en valores orientadas a la preparación de una ciudadanía activa y democrática; fomentar la educación democrática de la ciudadanía y la práctica del pensamiento social crítico; y relacionar teoría y práctica con la realidad del aula y del centro.

El conflicto a representar en el Teatro-Foro se ha gestionado de distinta forma en los diferentes años, ya que no ha sido el grupo-clase, como señala Boal, quien lo ha consensuado ni ha escrito la antipieza para representar ante el grupo. Hemos hecho una adaptación por los condicionantes de los tiempos en los que se desarrolla la asignatura y variaciones para acercarnos más a la propuesta de Boal. Así en los cursos académicos 2013-14 y 2014-15 el conflicto fue elegido por el profesorado, atendiendo a cómo se había ido desarrollando el contenido de la materia y qué cuestiones se habían planteado relevantes en el trabajo de la misma o atendiendo a características del grupo (resistencias ante determinadas cuestiones, posturas psicologicistas ante determinadas problemáticas, etc.), considerando la profesora que era necesario trabajar un determinado conflicto. En los cursos 2015-16 y 2016-17 se le solicitó al alumnado el conflicto a tratar, fueron distintas las temáticas o problemas, se eligió uno que se planteó en un conflicto. Por último, en el curso 2017-18 se demandó al alumnado, organizado en pequeños grupos, que planteara un conflicto, así como el desarrollo del mismo (qué sucede, en qué espacios se desarrolla la acción, qué personas intervienen, etc.). Se tuvieron en cuenta los conflictos, no los problemas, y atendiendo a la información sobre el desarrollo de los mismos, elaborábamos las minipiezas o más concretamente las antipiezas para representar ante el grupo-clase, concretamente fueron tres. Se presentaron estas al grupoclase que decidió cuál trabajar, asimismo se explicó por qué los problemas que algunos grupos presentaron no fueron tenidos en cuenta, lo que nos permitió tratar la diferencia entre problema y conflicto y exponer que es este el que se trabaja en el Teatro-Foro, introduciendo en qué consiste este. Tras esta introducción se desarrolla el Teatro Foro, se dedica una media hora o cuarenta y cinco minutos a ensayar la antipieza con alumnado voluntario mientras que el resto realiza ejercicios actorales, que preparan el cuerpo y lo desinhibe. A continuación, se representa ante el grupo-clase. Sus compañeros y compañeras actuando como espect-actores tratan de resolver el conflicto presentado, utilizando los contenidos trabajados en clase -igualdad, democracia, justicia, etc.-, mediante la acción. Los alumnos y las alumnas, que son en su conjunto los protagonistas, representan -lo que hubieran dicho a través de la palabra- para combatir la opresión, es 
decir, a través de la acción. El grupo va analizando si la acción o acciones solucionan el conflicto planteado, las consecuencias de las mismas, permitiendo conocer "el arsenal de los opresores y las posibles tácticas y estrategias de los oprimidos. El foro es un juego, es lúdico, una manera de aprender los unos con los otros" (Boal, 2015, p. 72). El Teatro-Foro, como afirma Boal (2015) es pedagógico porque posibilita el aprendizaje conjunto en la búsqueda de soluciones y en la invención de nuevas formas que hagan frente a la opresión.

\section{Experiencias desarrolladas en la práctica del Teatro-Foro}

A lo largo de estos años, los temas y conflictos de poder elegidos por el alumnado coincidían, por una parte, con los propios de la enseñanza universitaria y, por otro, con los que caracterizan la problemática en una educación no democrática. Podemos agrupar los temas experimentados en:

a) Asuntos derivados de la propia estructura del sistema pedagógico dominante que prima, por ejemplo, que la evaluación se realice a través de procedimientos individuales y competitivos, centrada en los resultados como los exámenes, y las clases sean definidas mediante el uso de libros de texto. Las propuestas que se basan en otras formas de evaluar, más formativas y centradas en el proceso de aprendizaje son consideradas inadecuadas. Se trata de conflictos de dominación que tienen su efecto en la formación y valorización.

b) Temas que proceden de las contradicciones entre sistema educativo, ligado al funcionamiento del sistema social dominante, y educación integral de los individuos. En ese punto, muchas de las sesiones de Teatro-Foro indagaron en el llamado fracaso escolar convirtiéndolo en una desigualdad de poder del currículum oficial y el currículum deseable. Esto afectaba, igualmente, a los contenidos y su orientación política, recogidos en la planificación de la enseñanza que refleja los intereses de una parte de las clases que conforman nuestras sociedades.

c) Otro conjunto de conflictos tiene que ver con el propio espacio de la escuela y la universidad: aunque es posible encontrarlos fuera de las mismas (el acoso, el hambre o el rechazo de géneros no normativizados), se convierten en conflictos de poder cuando se desarrollan en el marco específico del centro de enseñanza, por las estructuras jerárquicas que definen los papeles y comportamientos de los colectivos que forman parte del mismo. 
La valoración del alumnado participante en estos años de experiencias del Teatro Foro se ha recogido a través de los coloquios posteriores a las sesiones de Teatro-Foro que se han realizado y de tutorías colectivas. En ambos casos se trataba de recabar información acerca de "qué ha supuesto para ti la experiencia", "qué puede hacerse con la misma para desarrollar en el aula" y "qué límites encuentras en esta práctica". En la mayoría de los casos, la experiencia le muestra la dificultad de solucionar realmente los conflictos planteados, especialmente cuando, por la forma teatral, nos implican física e intelectualmente. Encuentra una complejidad de las situaciones que no corresponde con las soluciones imaginarias que suelen utilizarse. Este desnivel es algo muy destacado en las tutorías colectivas. Señala las dificultades que tiene dado que suele convertir un conflicto político en un problema moral. Respecto a qué puede hacerse con la técnica en el aula, el alumnado observa que puede utilizarse para resolver problemas de respeto en el aula. Lo encuentra adecuado para el desarrollo de temas, pero ve límites en tanto que lo que se soluciona en el teatro no tiene una traducción directa en la realidad, pues las ideas tienen raíces más amplias que las meramente enunciativas.

\section{CONCLUSIONES}

El Teatro-Foro como herramienta metodológica nos ha permitido eliminar diferentes dualidades y contradicciones en la formación inicial docente en el marco de un programa de formación para la democracia y la justicia social en educación. Entre estas dualidades destacamos:

a) Teoría-práctica. El alumnado ha podido experimentar la unión teórica-práctica, la teoría le permitió explicar realidades concretas, dotarlas de sentido, cuestionarlas y llevar a la práctica la teoría de una educación democrática, comprobar que teoría y práctica se informan mutuamente, alcanzando una relación dialéctica entre ellas (Freire, 1975b), que la teoría de la educación emancipadora sea la misma cosa que la práctica emancipadora, ambas se convierten en una.

b) Investigación-docencia. La investigación teórica y la investigación práctica son elementos cruciales de la docencia. El Teatro-Foro posibilitó al alumnado utilizar una herramienta metodológica, con el objeto también de que esta sea utilizada en su futuro ejercicio profesional, para indagar en las relaciones de dominación que obstaculizan la creación y desarrollo de escuelas democráticas, dando la posibilidad de que se convierta en uno de los agentes de una comunidad investigadora (alumnado centros educativos, familias, etc.), 
indagando sobre conflictos contextualizados, abriendo caminos de reflexión y acción transformadora. El Teatro-Foro generó un espacio en el que la docencia se insertó en el proceso de investigación. Una "real" docencia en el marco de una educación liberadora es investigación, en tanto que no se reduce al conocimiento existente, sino que está interesada en un conocimiento aún no producido que permita avanzar en el marco de dicha educación.

c) Enseñanza-aprendizaje. Si partimos de la idea de Freire (1992, p. 90) de que "nadie educa a nadie, así como nadie se educa a sí mismo, los hombres se educan en comunión, mediatizados por el mundo", y si el objetivo es potenciar el aprendizaje, un aprendizaje útil en el marco del desarrollo de un proyecto de educación para la transformación educativa y social, el aula universitaria se convirtió en el desarrollo del Teatro-Foro en una comunidad de aprendizaje que buscó, discutió, analizó, explicó y reflexionó sobre realidades y problemáticas concretas, que indagó en el conocimiento existente y que produjo conocimiento conjuntamente a partir de situaciones reales para seguir avanzando en el proyecto pedagógico de educación emancipadora.

d) Aprendizaje individual-aprendizaje colectivo y cooperativo. El Teatro-Foro ha permitido desarrollar procesos de aprendizaje colectivo en la comprensión de los hechos, favoreciendo la comunicación, la interacción y participación del alumnado menos activo, aquel que se denomina "gris", que pasa desapercibido en el grupo. Además, en su desarrollo se ha constatado la afirmación de Freire (1998, p. 101): no existe la absolutización de la ignorancia ni absolutización de la sabiduría, dado que "nadie ignora todo, nadie sabe todo".

e) Educación bancaria-educación problematizadora. Si bien en esta dualidad la educación bancaria y la educación liberadora serían los dos polos opuestos en un continuum de posibilidades, en las que nos podemos encontrar prácticas más cercanas a un modelo bancario y prácticas más innovadoras, dirigidas a una educación problematizadora tanto en la escuela como en la universidad. En esta encontramos aulas en la que se problematiza la realidad educativa, pero sin que lleguen a constituir lo que Freire consideraba por praxis, al quedarse en el plano del discurso crítico y no de la acción, que por otra parte es una crítica que la propia pedagogía crítica se realiza. El Teatro-Foro permite la praxis para la resolución del conflicto planteado. 
f) Lo intelectual-lo emocional y lo corporal. El Teatro Foro integra las distintas dimensiones del ser humano: lo intelectual, lo corporal y lo emocional, como un todo sin división posible. En este sentido, Freire (2012) afirmaba que

es preciso atreverse a decir científicamente que estudiamos, aprendemos, ensañamos y conocemos con nuestro cuerpo entero. Con los sentimientos, con las emociones, con los deseos, con los miedos, con las dudas, con la pasión y también con la razón crítica. Jamás solo con esta última. Es preciso atreverse para jamás dicotomizar lo cognitivo y lo emocional (p. 26).

Esta integración ha posibilitado que alumnos y alumnas que no intervenían en el aula participaran, ofreciéndonos información de sus procesos de aprendizaje, durante la sesión de Teatro-Foro, teniendo una actitud más activa posteriormente durante el trabajo de la asignatura.

\section{NOTAS}

1 Por "oprimido", Boal entiende aquellas situaciones en las que "alguien utiliza el poder que le da la fuerza o su estatuto social, económico o incluso cultural, para reducir a alguien a la pasividad, a la sumisión, a la condición de objeto" (Boal, 2001, p. 188). Su proyecto forma parte, por tanto, de la larga tradición del Teatro Político que se inicia en el siglo XIX. Cf. De Vicente, 2013.

2 "No es ningún secreto que el Teatro del Oprimido debe su nombre a la Pedagogía del Oprimido, que Paulo Freire había publicado diez años antes. Nos conocimos en 1960 y desde entonces hubo una larga amistad entre nosotros" (Boal, 2001, p. 188).

3 "La dicotomía espectador-actor no es innata. Surgió, con el tiempo, en muchas sociedades. La idea de que algunos, los elegidos, sean actores, es una idea opresiva" (Boal, 1982, 1, p. 235).

4 "Educación, al contrario, consiste en una relación dialéctica en que la sociedad educadora no solo permite, sino que necesita que el educando actúe como sujeto, considerando que este no va a ser asimilado por una sociedad ya hecha, inmodificable, sino que la viene a transformar según sus propias necesidades y anhelos" (Boal, 1975, p. 148).

5 Se encarga de explicar las reglas del juego, estimular al público y animar a la intervención.

6 Cf. García Gómez, 2015.

7 Se trabaja de forma interdisciplinar con la asignatura "La innovación educativa en la Educación Primaria", que se imparte en el mismo curso y cuatrimestre.

8 Entiéndase por conflicto aquel hecho o conjunto de hechos que alteran radicalmente la trayectoria vital, emocional, intelectual, etc., de los sujetos (personajes), que están en oposición en una situación concreta. El conflicto es distinto al problema, este no alteraría radicalmente la trayectoria, sino que la obstaculizaría. 


\section{REFERENCIAS BIBLIOGRÁFICAS}

Boal, A. (1975). Técnicas latinoamericanas de teatro popular. Buenos Aires, Argentina: Corregidor.

Boal, A. (1982). Teatro del oprimido. (2 vv.) México, México: Nueva Imagen.

Boal, A. (2001). Boal conta Boal. Barcelona: Institut del Teatre.

Boal, A. (2015). Juegos para actores y no actores (6a ed.). Barcelona: Alba.

Calvo, A.; Haya, I. y Ceballos, N. (2015). El Teatro Foro como estrategia pedagógica promotora de la justicia social. Una experiencia de formación inicial del profesorado en la Universidad de Cantabria. Revista Interuniversitaria de Formación del Profesorado, 29(1), 89-107.

Carbonell, J. (2001). La aventura de innovar. Madrid: Morata.

Connell, R. (1997). Escuelas y justicia social. Madrid: Morata.

Contreras, J. (1997). La autonomía del profesorado. Madrid: Morata.

De Vicente, C. (2013). La escena constituyente. Teoría y práctica del Teatro Político. Madrid: Centro de Documentación Crítica.

Freire, P. (1975a). ¿Extensión o comunicación? La concientización en el mundo rural (2a ed.). Buenos Aires, Argentina: Siglo XXI.

Freire, P. (1975b). Acción cultural para la libertad. Buenos Aires, Argentina: Tierra Nueva.

Freire, P. (1992). Pedagogía del oprimido (12a ed.). Madrid: Siglo XXI.

Freire, P. (1997). A la sombra de este árbol. Barcelona: El Roure.
Freire, P. (1998). La educación como práctica de la libertad (9a ed.). Madrid: Siglo XXI.

Freire, P. (2001). Pedagogía de la indignación. Madrid: Morata.

Freire, P. (2005). La educación en la ciudad (3a ed.). México, México: Siglo XXI.

García Gómez, T. (2015). Introducción. En P. Freire, Pedagogía liberadora. (pp. 9-82). Madrid: Los Libros de la Catarata.

García Gómez, T. (2018). Bases del derecho a la educación: La justicia social y la democracia. Revista Internacional de Educación para la Justicia Social (RIEJS), 7(1), 159-175. https://doi.org/10.15366/ riejs2018.7.1.008

Giroux, H. y McLaren, P. (1990). La educación del profesorado como espacio contrapúblico: apuntes para una redefinición. En T. Popkewittz (Ed.), Formación de profesorado (pp. 244-271). Valencia: Universidad de Valencia.

Grundy, S. (1998). Producto o praxis del currículum. Madrid: Morata.

Gutiérrez, F. y Prieto, D. (2002). La mediación pedagógica. Xàtiva, Valencia: Diálogos.

Huerta-Charles, L. (2008). Pedagogía del testimonio: reflexiones sobe la pedagogía de la pedagogía crítica. En P. McLaren y J. Kincheloe (Eds.), Pedagogía crítica (pp. 340-355). Barcelona: Graó.

Kincheloe, J. (2008). La pedagogía crítica en el siglo XXI: evolucionar para sobrevivir. En P. McLaren y J. 
Kincheloe (Eds.), Pedagogía crítica (pp. 26-69). Barcelona: Graó.

Liston, D. y Zeichner, K. (1997). Formación del profesorado y condiciones sociales de la escolarización. Madrid: Morata.

Pérez Gómez, Á. (1995). Autonomía profesional del docente y control democrático de la práctica educativa. En VV. AA., Volver a pensar la educación. Vol. II. Prácticas y discursos educativos (pp. 339-353). Madrid: Morata.

Pérez Gómez, Á. (1992). La función y la formación del profesor/a en la enseñanza para la comprensión. Diferentes perspectivas. En J. Gimeno y Á. Pérez Gómez, Comprender y transformar la enseñanza (pp. 398-429). Madrid: Morata.
Popkewitz, T. (1990). Conocimiento e interés en los estudios curriculares. En T. Popkewittz (Ed.), Formación de profesorado (pp. 304-321). Valencia: Universidad de Valencia.

Stenhouse, L. (1996). La investigación como base de la enseñanza. Madrid: Morata.

Weiner, E. (2008). La pedagogía crítica y la crisis de la imaginación. En P. McLaren y J. Kincheloe (Eds.), Pedagogía crítica (pp. 89-116). Barcelona: Graó.

Zeichner, K. (1995). Los profesores como profesionales reflexivos y la democratización de la reforma escolar. En VV.AA., Volver a pensar la educación. Vol. II. Prácticas y discursos educativos (pp. 385-398). Madrid: Morata. 


\section{PERFIL ACADÉMICO Y PROFESIONAL DE LOS AUTORES}

Teresa García Gómez. Doctora en Pedagogía por la Universidad de Granada. Profesora titular del área de Didáctica y Organización Escolar de la Universidad de Almería. Autora de los artículos "Bases del derecho a la educación: La justicia social y la democracia" (2018) y "Trayectorias profesionales comprometidas con la educación democrática" (2018). Editora de FREIRE, Paulo: Pedagogía liberadora (2015). Líneas de investigación: coeducación; relaciones de poder, educación y género; alternativas pedagógicas democráticas; educación democrática e innovación educativa.

César de Vicente Hernando. Coordinador del Centro de Documentación Crítica. Doctor en Filosofía y Letras por la Universidad Autónoma de Madrid. Profesor colaborador en el "Máster en Literaturas Hispánicas: Arte, Historia y Sociedad" (UAM) y del curso "Teoría y práctica del Teatro Político" (UCM). Director de Escena. Autor de los ensayos La escena constituyente (2013) y La dramaturgia política (2018). Línea de investigación principal: prácticas teatrales constituyentes.

Dirección de los autores: Teresa García Gómez

Facultad de Ciencias de la Educación

Departamento de Educación

Ctra. Sacramento, s/n

La Cañada de S. Urbano

04120-Almería (España)

E-mail: tgarcia@ual.es

César de Vicente Hernando

Paseo de la Estación, 18. Casa 37

28350-Ciempozuelos - Madrid (España)

E-mail: noviembre@nodo50.org

Fecha Recepción del Artículo: 5. Enero. 2019

Fecha Aceptación del Artículo: 22. Junio. 2019

Fecha Revisión para Publicación: 08. Julio. 2019 